\title{
Reflexões sobre a escrita na formação inicial de professores
}

\section{Reflections about writting in the initial formation of teachers}

\author{
Odisséa Boaventura de Oliveira*
}

\begin{abstract}
RESUMO
O presente estudo busca nos textos produzidos por licenciandos ao analisarem aulas ministradas por eles a manifestação de subjetividades, singularidades e identidades ao se verem no papel de professor. Toma-se como fundamentação as noções de processos identitários e gêneros textuais. Observa-se que alguns licenciandos destacam as falhas cometidas na condução de suas aulas procurando justificá-las. Outros licenciandos destacam o papel satisfatório de suas práticas se identificando à profissão. Discute-se ainda sobre a contribuição da escrita de gêneros diferenciados na formação docente.

Palavras-chave: processo identitário; subjetividade; formação de professor; gênero textual.
\end{abstract}

\begin{abstract}
This study searches in the texts written by future teachers about their classes for the manifestation of subjectivities, singularities and identities when they assumed their teacher role. The theorical support is based on notions of identitary processes and textual genres. It's observed that some students write about faults in their classes trying to explain them. Other students write about the satisfaction with their classes and their identification with the profession. This study also discusses about the contribution of writing of different genres in the teacher formation.
\end{abstract}

Keywords: identity process; subjectivity; teacher formation; textual genre.

* Programa de Pós-graduação em educação - UFPR. Email: odissea@terra.com.br 
Este estudo visa discutir a formação docente pelo prisma da linguagem, enfocando a escrita, o que nos leva a tomar da Análise de Discurso a concepção de linguagem como matéria estruturante dos sujeitos, ou seja, como uma "tomada de posição", segundo Pêcheux, o que equivale reconhecer que os lugares ocupados nas relações sociais definem os significados das palavras, delimitando o que cada falante (ou escrevente) manifesta e como o faz. Isso implica que nenhum sentido, no discurso oral ou escrito, é dado a priori, mas constituído e considerado "em relação a", isto é, as palavras mudam de sentido conforme a posição de quem as emprega. Por conta disso, refletir sobre posições assumidas pelo sujeito no uso da linguagem implica em trazer à tona noções de subjetividade e identidade, vale dizer, sua própria autopercepção e autorreconhecimento, o que se dá por meio de pensamentos e emoções conscientes e inconscientes, como demonstraremos.

Diferentemente de nós, há também uma corrente de investigação bastante influente nos meios acadêmicos relativa à formação do professor reflexivo, e que, para isso, vem investigando os instrumentos e mecanismos que levam o docente a uma familiarização com ações e pensamento críticos. Para ela, a expressão escrita é vista como uma maneira de promover tal reflexão, ou de incitar estranhamento, na medida em que o professor descreve o que fez e o porquê de determinadas atividades. Nessa perspectiva, muitos autores apontam a escrita narrativa como uma forma de registro das impressões sobre a sala de aula, na medida em que é utilizada de maneira informal, geralmente refletindo as dimensões subjetivas das perspectivas do professor, ou seja, possibilitando o registro dos pensamentos e sentimentos experienciados que podem fornecer subsídios ao seu trabalho (SILVA; DUARTE, 2001). Além disso, essa forma de registro é vista como importante para a construção da autoconfiança, percepção a respeito do processo ensino-aprendizagem e construção de novos significados para a prática de ensino (CRISTÓVÃO, 2002).

Nessa linha, Fiad e Silva (2000) defendem o diário como um gênero que se caracteriza pela exposição e difusão da vida privada, portanto trata-se de uma "fala escrita", uma vez que o locutor escreve para si mesmo ou dirige-se a um outro com quem convive no "campo da linguagem" ou a alguém eleito no “campo empírico". Para essas autoras o diário oportuniza a relação teoria-prática, uma vez que o produtor deste gênero pode relatar articulações com leituras e estudos realizados no curso e seu relacionamento na escola, dialogar com suas representações o que pode levar à sua conscientização e revisão de procedimentos. Mas para que o diário contribua para a formação reflexiva, Silva e Duarte (2001) ressaltam que as descrições de acontecimentos precisam ultrapassar o nível do simples relato e contemplar a análise das causas e consequências de suas ações para que o professor se transforme em investigador de si próprio, 
iniciando como narrador e posteriormente assumindo a posição de analista crítico dos registros elaborados. Por fim e em geral, esses estudos consideram que a escrita na formação docente deve se configurar em experiência compartilhada, ser concebida como espaço de troca (CARVALHO, 2002).

Por sua vez, na perspectiva por nós adotada, não concebemos a escrita dessa forma interativa, ou seja, para efeitos de promover trocas entre professor e alunos, nem segundo a pretensão de fazê-la instrumento de reflexão para o licenciando. De fato, nosso objetivo é o de identificar e descrever as impressões relativas às próprias práticas pedagógicas dos licenciandos em sua experiência docente de formação, bem como os sentidos que manifestam em seus relatos escritos sobre ela. Esse enfoque nos permite, adicionalmente, analisar o próprio discurso que a universidade aplica e imprime em quem passa por ela como estudante.

Assim, buscamos neste artigo compreender a "posição-professor" assumida nos textos dos licenciandos, destacando aspectos relacionados a esta atividade como a constituição de processos identitários, o gênero textual e as condições de produção da escrita, uma vez que, todo texto constitui representações, relações e identidades. Com estes conceitos analisaremos a produção escrita que se deu na disciplina Metodologia de Ensino, ministrada no $6 .^{\circ}$ período do curso de Ciências Biológicas quando os licenciandos ministraram aulas para alunos de uma escola rural no ensino fundamental e médio. Após esta produziram um texto analítico a respeito da linguagem utilizada, do enfoque dado ao conteúdo, da interação promovida com os alunos e da forma como se viram no papel de professor. Para isso, caminhamos na direção apontada por Riolfi e Alaminos (2007, p.305) quando afirmam que é importante "examinar as marcas que permitem supor a manifestação de um sujeito singular na escrita".

\section{Processos identitários}

Em lugar de adotar o termo "identidade" alguns autores preferem "processos identitários", pois traz a ideia de identidade não fixa, mas em constante fluxo de construção. Por assim dizer, um palco de lutas e conflitos, pois comporta a marca da ambiguidade do individual e do coletivo, do que é próprio e do que é alheio, do que é igual e do que é diferente, de permanência e de metamorfose, ora apontando para um polo ora para outro, numa síntese inacabada entre objetividade e subjetividade. Trata-se de um conceito que permite distinguir sujeitos e grupos, localizá-los no tempo e no espaço. Assim, identidade e subjetividade, conceitos relacionados à natureza do social e do sujeito, respectivamente, são 
indicativos de concepções teóricas que apontam para os modos de produção histórica dos sujeitos inseridos em práticas discursivas. O conceito de identidade toma como referência o estudo dos grupos sociais e da forma como se constituem, pressupõe a análise das diferentes dimensões nos modos de constituição histórica do sujeito (BALOCCO, 2007). Já o de subjetividade é pensado a partir do entrecruzamento de fatores sociais, linguísticos e culturais.

Riolfi e Alaminos (2007) abordam a identidade ou identificação, pelo âmbito da psicanálise, como sendo um laço emocional que uma pessoa estabelece com outra, isto é, quando toma alguém como sendo seu ideal, o que pode ser expressão de ternura ou de hostilidade. Segundo as autoras, a instalação de um processo identificatório abre a possibilidade da pessoa se reinventar e este jogo de identificações está em permanente construção de si e de seu trabalho. As autoras também descrevem os tipos de identificação propostos por Lacan, a saber:

Identificação à imagem proposta pelo outro: trata-se da identificação por meio da qual um sujeito pode vir a se compreender como sendo um eu, separado do outro do qual é, naquele instante da sua vida, objetivamente dependente. Ela permite a posterior construção de um dizer na primeira pessoa do singular [...]

Identificação ao desejo inconsciente: trata-se da identificação estruturante por meio da qual um sujeito toma alguém, que para ele é percebido como um sujeito desejante, como modelo. A condição de alguém vir a ocupar o lugar de um objeto copiado, portanto, é dar mostras de estar em permanente busca de algo que poderia vir a suprir a insatisfação do seu desejo. Lacan confere a essa identificação o poder de reintroduzir, como falta, o objeto perdido, responsável pela insatisfação [...] (RIOLFI; ALAMINOS, 2007, p. 303).

Por essas definições vê-se que a identificação está sempre relacionada à imagem do (proposta pelo) outro, aquela pela qual um sujeito pode vir a se compreender como sendo um eu, separado do outro, mas do qual é dependente. Essa identificação instaura, como visto, o campo que possibilita o desejo, proporciona ainda uma primeira separação do sujeito do outro e essa separação torna um querer subjetivado possível. Outra é a identificação ao desejo inconsciente, ou seja, o sujeito toma alguém, que para ele é percebido como um sujeito desejante, como modelo.

Segundo as autoras, Lacan afirma que só se responsabiliza por seu fazer aquele que sabe fazer, ou seja, aquele que constrói um estilo de conduzir a sua prática. Esta concepção, as autoras transpõem para o contexto da formação de 
professores, indicando que se responsabilizar pela própria prática implica em poder se autorizar a julgar a qualidade de seu fazer pelos resultados que obtém de seus alunos e não pela sua semelhança com o ideal ao qual estava identificado. Para elas, na formação de um novo professor, o processo identificatório é mobilizado e, idealmente, leva aquele que está em formação a construir um lugar próprio. Mas esta construção só se edifica caso esteja apoiada no andaime composto pelas múltiplas identificações colocadas em jogo ao longo de seu percurso.

Assim, concebemos que no campo do discurso pedagógico os professores constroem suas identidades por referência aos saberes teóricos e práticos, portanto mutáveis conforme o conjunto de valores ao qual se apropriam em determinados momentos. Dessa forma, a identidade está relacionada com a maneira e o modo de ser professor.

Por conta disso, nos textos produzidos pelos licenciandos, objetos dessa pesquisa, procuraremos compreender as imagens ou representações que eles têm de si, da futura profissão (as tarefas que lhes cabem, seus compromissos etc.), além das que eles têm dos alunos, já que estamos considerando que o sujeito se constrói pelo outro, para capturar os momentos de identificações do licenciando com o sentir-se professor. Enfocados os processos identitários, passemos aos gêneros textuais.

\section{Gêneros textuais}

Maingueneau (1989) aponta fatores importantes para pensarmos o papel da escrita, como a "deixis discursiva" referente ao EU (locutor discursivo), ao TU (destinatário discursivo), ao AQUI (topografia) e ao AGORA (cronografia), que definem a coordenada espaço-tempo da enunciação. Outro aspecto mencionado por ele é o lugar de onde se fala, enquanto determinante da identidade de cada indivíduo, sendo que este também ao enunciar garante sua autoridade institucional. Esta posição de onde fala o sujeito seria o lugar encenado no discurso, sendo a encenação uma das formas do real que só é acessado através do discurso.

$\mathrm{O}$ autor também reconhece contribuições do teatro quanto à ideia dos "papéis" que o locutor pode escolher para si ou para seu destinatário, estabelecendo a cenografia ou encenação de imagens que um remete ao outro no ato de comunicação. Para ele a Análise de Discurso enfatiza o lugar da enunciação, a topografia social dos falantes, de modo que a instância de enunciação constitui 
o sujeito e o assujeita, melhor dizendo, o lugar de onde se fala determina a identidade de cada indivíduo, sendo que este também ao enunciar se submete às regras.

Utilizando Maingueneau para interpretar os textos dos licenciandos apontamos elementos como a posição do enunciador, a deixis discursiva (espaço e tempo do discurso), o gênero adotado, que possibilitam compreender aspectos que permeiam as ações e os discursos dos futuros professores. Ele ainda associa gêneros textuais aos suportes de formulação dos textos, isto é, à sua forma de apresentação, ao modo de manifestação material dos discursos, por exemplo, panfletos, folders, livros, cartaz etc. Neles, o sujeito se manifesta a partir de posições enunciativas, marcadas pelo critério institucional, como participante de uma comunidade discursiva. Para ele, não se separa o que é dito das condições materiais e institucionais do dizer, pois eles remetem aos lugares enunciativos (de onde se fala).

Quanto aos gêneros textuais percebemos que grande parte das pesquisas que enfoca a escrita na formação aborda a utilização de diários, pois acredita que eles auxiliam na reflexão sobre suas experiências, suas crenças, decisões tomadas, atitudes e ações. Também defendemos que a escrita de gêneros não acadêmicos na formação inicial de professores pode contribuir para a assunção de um discurso próprio sobre a prática docente. Por isso enfocaremos adicionalmente a contribuição de outros gêneros escolhidos pelo licenciando para expressar sua percepção sobre si no papel de professor. Antes, porém, vale ressaltar a situação em que se deu as referidas produções escritas.

\section{Condições de produção}

Destaquemos as condições em que se deu a produção dos textos considerando o licenciando e o contexto da disciplina Metodologia de Ensino. Esta disciplina foi ministrada no $6 .^{\circ}$ período do curso de Ciências Biológicas e contou com uma carga horária de 90 horas no semestre. Os conteúdos abordados foram: Tendências pedagógicas e o histórico da disciplina ciências no Brasil; Questões curriculares: Parâmetros Curriculares Nacionais (PCN) e Diretrizes Curriculares do Estado do Paraná; Concepções de ciência e o ensino de ciências: Bacon, Popper, Khun, Bachelard; Enfoques de conteúdos: Ciência-Tecnologia-Sociedade (C-T-S), História da ciência, Cotidiano; Estratégias de ensino: Aula expositiva dialogada, Leitura, Escrita, Vídeo, Informática, Atividade lúdica, Estudo de campo, Experimentação, Resolução de problema; Avaliação; Livro didático. 
Foi proposto, em meados do semestre, que os licenciandos fossem para a escola observar aulas de professores de Biologia/Ciências orientados por um roteiro que contemplava a interação professor-aluno-conhecimento, a dinâmica comunicativa na sala de aula, a utilização de recursos didáticos e a abordagem do conteúdo. Após assistir essas aulas deveriam elaborar um relatório descritivoanalítico, relacionando a prática docente à teoria estudada.

Outra atividade desenvolvida relacionada diretamente à prática docente foi a de ministrar uma aula. Esta foi realizada em uma escola rural de um município próximo à Curitiba, Campo Magro. Os licenciandos se organizaram em grupos e a escola em questão cedeu todas as aulas do período para eles. Para a análise desta atividade foi sugerido que observassem os seguintes aspectos: Conteúdo (enfoque, profundidade, exemplificação, relações e objetivos); Uso de estratégias (o que, como, motivação e facilitações produzidas); Linguagem (adequação, tom, vícios, analogias); Interação com os alunos (questionamentos feitos, motivação); Mudanças necessárias. Estes aspectos foram sugeridos em função do programa e objetivo da disciplina que é o de possibilitar ao licenciando a reflexão teórica acerca da metodologia de ensino na área das ciências naturais, a fim de que elabore propostas coerentes com as necessidades atuais. Foi solicitado que produzissem um texto relatando essa experiência por meio de um gênero diferenciado, como carta, diário, artigo de jornal etc.

\section{Análise: delimitações e desenvolvimento}

Os gêneros efetivamente utilizados pelos licenciandos, para nossa surpresa, foram: diário, boletim policial, crônica, carta, relato (de guerra, de sonho), relatório, conto, poesia, texto religioso, edital de concurso, bula de remédio, entrevista, artigo de revista. Também foram utilizados diferentes suportes (veículos) como jornal, livro, e-mail, slides e blog.

Nesses textos os licenciandos denominaram a escola, local em que se deu para muitos a primeira experiência docente, de diferentes modos dependendo do gênero escolhido. Por exemplo, no texto religioso, a escola foi descrita como "o monte do saber"; em um diário de bordo como "um outro planeta", já no relato de guerra como "um campo de batalha". Enfim, o espaço escolar foi abordado como um palco em que ocorrem diferentes "aventuras".

Uma curiosidade foi que desde a produção das capas dos textos, passando pela escolha dos títulos, tudo estava relacionado com a "estória construída". Alguns alunos fizeram trocadilho com o nome da professora e o local (uma escola 
rural de difícil acesso), por exemplo: "2007- Uma odisséia na escola”. Outro foi "Um grito por ajuda", associado à imagem da obra de Munch (O Grito). "Crônicas de uma aula" trouxe uma imagem da bandeira brasileira com uma toga protegendo a faixa com o lema Ordem e Progresso. "Era uma vez em Campo Magro", referindo-se ao município da escola. De certa forma os licenciandos procuraram sugerir desde o primeiro contato do leitor com o texto uma síntese do que se passa em seu interior.

Quanto ao tempo em que teria ocorrido a "estória construída", em alguns textos o locutor se posicionou em um tempo futuro olhando para o passado (o momento de ocorrência da aula). Em outro, o narrador fez uma previsão do que ocorreria no dia seguinte à aula. Também há diferenças quanto ao lugar desse narrador, alguns licenciandos se colocaram no lugar do aluno comentando como ele deve tê-lo visto no papel de professor. Num conto a licencianda se colocou no lugar de sua própria mãe fazendo um jogo entre o futuro e o passado ao relatar sua experiência para a filha. No boletim policial toda a experiência docente da licencianda foi narrada do ponto de vista de uma vítima de sequestro. Em todas essas produções foi possível observar, principalmente, a manifestação dos sentimentos de expectativa, de nervosismo, de ansiedade, de frustração na primeira experiência de docência de cada um deles. Apesar disso, outro aspecto que chamou a atenção foi o envolvimento com a atividade docente, despertando-os para a crítica perante a situação educacional e para a função do professor.

Como visto, são vários os aspectos abordáveis na análise dos gêneros, contudo, para efeito deste artigo centraremos nossa atenção nas identificações que eles possibilitam ao locutor. Alguns textos destacaram especialmente as dificuldades encontradas na aula, apontando-as como faltas na execução de uma tarefa que seria a de obter o máximo de sucesso, como descrito abaixo:

Acho que minha maior falha foi quanto às estratégias utilizadas. Devido ao nervosismo (tenho sério problema em falar em público), acabei deixando de lado todas as táticas que eu pretendia usar. Embora eu tenha exposto os problemas de forma cientifica, falhei gravemente ao não propor situações problema e não estimular os alunos a formular hipóteses para resolução desses problemas. Não utilizei nenhum material visual, como apresentação em retro-projetor, ou desenhos esquemáticos no próprio quadro negro. Também não fiz anotações dos pontos principais da minha exposição no quadro negro, para facilitar a fixação dos alunos. A exposição do assunto não foi feita de forma dialogada e o tom usado foi relativamente ritmado, em alguns momentos, causando eventual desatenção dos alunos. Por outro lado, a motivação e a facilitação foram feitas através de exemplos simples e de fácil compreensão por parte do aluno, sem uso de metáforas muito complexas. Acho que se pudesse mudar algo nessa aula, com toda 
certeza, seria meu nervosismo e o meu nível de preparo, coisas que me atrapalharam muito ao ministrar essa aula (A, grifos nossos).

É interessante observar que o relato desta licencianda foi pautado na justificação, do tipo: "isso decorreu em função de..., mas também há que se considerar que...”. Ou seja, reconhece que as falhas ocorreram, mas apresenta uma justificativa, o que chama a atenção para as ocorrências positivas. Dessa forma a locutora justifica que, por conta de seu estado emocional gerado pela dificuldade em falar em público, não fez o que havia planejado, como "as táticas que eu pretendia usar", segundo suas palavras.

Para efeito de análise destacamos em negrito os termos que apontam a negatividade (falha, não) e os que apontam implicação (devido a, embora, por outro lado). Eles indicam que há uma contraposição entre o realizado/não-realizado: exposição de forma científica/não formulação de hipóteses pelos alunos. Indicam também que há motivação e facilitação/não utilização de recursos (nem mesmo do quadro negro). A locutora destaca ainda que utilizou uma linguagem científica, embora devesse ter adotado a problematização como metodologia de ensino, ou seja, aponta para a necessidade de certa coerência conteúdo-forma. Também reconhece que não utilizou recursos visuais, mas que a motivação e facilitação da aprendizagem se deram por conta da exemplificação utilizada. Há ainda subentendida a noção de que a visualização do conteúdo atua como facilitadora da aprendizagem.

Por sua vez, posicionamentos relativos à participação do aluno, que poderia ser estimulada por meio da problematização, e ao uso de recursos visuais na tentativa de facilitar a aprendizagem por meio da relação com o cotidiano, expõem a influência da teoria aprendida e enfatizada durante a formação da licencianda. Seu texto também evidencia as marcas do que importa a ela como professora, pois se no início diz que sua maior falha foi em relação às estratégias, ao final pensa que poderia ter evitado se apresentasse melhor nível de preparo e se pudesse alterar seu estado emocional.

O texto mostra que a licencianda está atendendo prontamente às solicitações do professor formador: que analisasse como se deu a utilização de estratégias didáticas, da linguagem, da interação com os alunos e as mudanças necessárias. Mas foi justamente em meio a isso que ela manifestou o que de fato valoriza na atuação do professor: seu nível de preparo, que está relacionado à exploração do conteúdo, sua profundidade, isto é, ao conhecimento que o professor detém a respeito daquilo que pretende ensinar. Isso pode ser confirmado pelo fato dela ter dito que expôs os problemas de maneira científica, mas que não usou 
metáforas muito complexas.

Se por um lado a licencianda aponta suas falhas, por outro ela destaca os aspectos positivos de sua atuação, numa tentativa de mostrar as identidades contraditórias que a constitui, como se quisesse dizer "eu não fiz isso, mas sei que deveria fazê-lo, no entanto fiz aquilo e você deve reconhecê-lo". Outro recurso que adota em seu texto é o de procurar atenuar suas limitações como o fato de que em "alguns momentos" o tom ritmado de sua voz causou "eventual" desatenção nos alunos.

É possível observar que a posição de professor assumida neste texto é marcada pela identificação com o outro (aluno e professor-formador), pois o julgamento de sua prática se dá em função dos resultados atingidos.

Uma segunda licencianda também destacou em sua prática a baixa interação com os alunos e a justificou em função da característica de sua voz e do tempo disponível para o desenvolvimento da aula:

O conjunto de características do professor somado ao modo de como a aula é ministrada podem variar muito a atenção e a motivação dos alunos frente ao assunto abordado. [...] A aula foi muito pouco dialogada. A falta de interação com os alunos ocorreu, provavelmente, devido a tonalidade da voz, que além de muito baixa, se manteve num único tom. O resultado da aula se tornou essencialmente expositiva, já que praticamente não houve o uso de estratégias. [...] $\mathrm{O}$ tempo, de fato, não abriria muito espaço para o assunto abordado por mim, porém, estratégias como um trabalho com informações adicionais, atividade lúdica simples ou mesmo a leitura/ escrita (não somente cópia), poderia ser uma ferramenta de auxílio. O levantamento de problematização, segundo os PCNs, é uma forma eficaz de instigar a curiosidade e levar ao raciocínio lógico do aluno ao levantar hipóteses para a solução do problema. Isto se encaixaria muito bem. Houve, em alguns momentos e sempre que possível, o uso de exemplos, mas poderia ter trabalhado mais intensamente com este recurso. Exemplos cotidianos auxiliam no interesse do público (C, grifos nossos).

O texto desta licencianda, como se pode notar, é menos justificativo do que o da anterior, caminha no sentido de apontar as faltas e a indicar que os poucos aspectos positivos visualizados não foram suficientes, o que é perceptível nos comentários feitos após o emprego dos termos destacados por nós em negrito (já que, porém, mas). A contraposição que merece destaque é a do realizado/ poderia ser realizado: o tempo permitiu que fizesse isso, mas poderia ter usado outras estratégias, no caso informações adicionais, atividade lúdica, leitura, 
escrita; usou exemplos do cotidiano, mas poderia ter usado mais.

Neste caso a licencianda também observa a pequena interação com os alunos, sendo que a exposição ocupou o lugar do diálogo, talvez por falta de produção de situações problematizadoras por meio de exemplos do cotidiano. Nesse ponto, são coincidentes com os aspectos apontados pela licencianda A, citada anteriormente. No entanto, C recorre ao PCN, um documento oficial (que o professor-formador apresentou e utilizou nas aulas de Metodologia) para justificar a contribuição que esta estratégia poderia ter oferecido.

Em síntese, a licencianda manifesta ou identifica-se com a imagem de professor como responsável pelo envolvimento do aluno com o conhecimento, isto é, reconhecendo que as características do professor e de sua aula influenciam diretamente a participação do aluno. O que aponta para uma identificação marcada pelo fim último do ensino, a aprendizagem dos alunos, cuja origem está na constituição de um sujeito-professor que responde por seus atos.

O próximo texto, como o primeiro, procura justificar as falhas percebidas, neste caso em relação ao conteúdo e à gesticulação, expressa nos termos "mas" e "porque":

Acho que o conteúdo poderia ter sido mais aprofundado e mais bem explorado; mas considerando que os temas dos grupos só foram realmente divididos na véspera, achei bastante razoável. [...] fiz diversos comentários do ambiente doméstico, justamente porque o grupo buscava ministrar uma aula que tivesse alguma utilidade prática, que fosse capaz de mudar algo na consciência daqueles alunos. Reparei que eu gesticulo bastante, mas como os movimentos não são do tipo repetitivos, achei razoavelmente bom, dá movimento, dinamismo. Utilizei duas transparências, e poderia ter utilizado o quadro como recurso, por exemplo, para ficar mais didático e para ajudar os alunos, pois notei que vários anotavam o que dizíamos. Além disso, o quadro ajuda a passar a sensação de aula propriamente dita. Os alunos estavam bastante interessados e faziam muitos questionamentos, o que gerou uma boa impressão, e servia de estímulo. Gostaria de ter mais preparo para poder responder a todas as dúvidas levantadas, justamente por eles se mostrarem tão interessados, e nem sempre nós estávamos aptos a respondê-las integralmente ( $\mathrm{L}$, grifos nossos).

Este texto curiosamente reconhece que a participação do aluno motiva o professor. Em outro momento também expressa o que, para ela, representa uma aula: o uso do quadro negro. Esta licencianda, assim como a primeira, comenta sobre seu preparo, ou despreparo, para responder às dúvidas dos alunos, o que passa pela questão do domínio do conhecimento e do professor como 
agente responsável pela aprendizagem. Também, nesse caso, reflete a imagem do professor como aquele que não pode ter dúvida, que não pode expor suas fragilidades, que não tem o direito de não conhecer. Com essa imagem em vista, isto é, como ideal, a licencianda expressa suas próprias identificações e denuncia o quanto há de coletivo, isto é, de comum entre os licenciandos. Expressa assim uma identidade que funciona como chave de leitura, queremos dizer, de julgamento e avaliação sobre seu próprio desempenho e sobre suas metas futuras como educador.

O próximo texto traz também uma justificativa das falhas em função do tempo de organização da aula e de seu estado emocional:

O enfoque das doenças foi muito superficial, as doenças mencionadas apareceram de um modo geral, sem muitos detalhes específicos. Faltou apresentar sintomas e formas de tratamento de cada doença. Por ter sido tudo feito de última hora, até que ficou razoavelmente bom, apesar de faltar um pouco de conteúdo. [...] eu poderia ter usado o quadro-negro, mas por nervosismo, nem pensei nisso. [...]. Percebi que não consigo ficar com as mãos paradas. Mexo as mãos também por nervosismo. Não estou acostumada a dar aula e sinceramente não gosto, pra mim, quanto mais rápido for, mais rápido acaba. Sobre a interação com os alunos, essa só foi feita no final da apresentação, quando eu perguntei se eles tinham alguma dúvida. No decorrer da aula, eu não deixei espaço para que eles falassem ou me questionassem. O problema de falar de doenças em geral, é que fica chato e cansativo ficar falando os sintomas de todas as doenças, os alunos não prestam muita atenção depois da terceira, e esquecem a maioria das coisas faladas. Isso é experiência própria (M, grifos nossos).

Neste caso a licencianda observa que não ocorreu aprofundamento do conteúdo em sua aula e que isso se deu, em parte, em função de sua experiência como aluna que julga cansativo quando se especifica demais o conhecimento relacionado às doenças, também aponta que não fez uso do quadro negro e que gesticulou as mãos excessivamente em função de seu nervosismo. Destaca ainda a não interação com os alunos, que pelo visto se deu por querer finalizar sua exposição rapidamente, uma vez que afirma não gostar de ministrar aulas.

Ela expressa, curiosamente, a voz do vivido e do experimentado enquanto sujeito-aluno justamente, entendemos, na tentativa de evitar proceder como o professor que considera inadequado, responsável pela aula chata, cansativa e causadora da desatenção e do baixo rendimento (o aluno esquece). É a afirmação de quem se coloca na posição dos seus alunos, uma crítica fundada sobre a imagem que os alunos fariam dela enquanto professora. 
Nessa linha crítica, a licencianda expõe seus sentimentos em relação à profissão, pois não quer segui-la, embora esteja cursando a modalidade licenciatura. Ressaltemos que essa é uma situação muito recorrente entre os alunos, por conta que a docência entre os alunos do curso de Ciências Biológicas ocupa frequentemente a segunda opção. Não cabe aqui discutir o porquê dessa rejeição, mas com certeza está relacionada à desvalorização da profissão, ou melhor, à imagem pública que a sociedade comporta do sujeito-professor e de suas condições de trabalho. O que funciona como mais um agente de formação da identidade, tanto positiva como negativa, do professor. Para alguns licenciandos, lutar contra essa situação é um estímulo, conforme veremos mais adiante. Para outros, essa identificação acaba por afastá-los da profissão docente.

$\mathrm{Na}$ análise desses fragmentos e pelos aspectos destacados percebe-se que a prática docente é sempre marcada por "fios discursivos" advindos da imagem que os licenciandos fazem de si mesmos (estar no lugar do professor), do outro (do professor-formador, dos alunos) e do objeto do qual falam (ser professor). Fios que se entrecruzam e tecem as identificações que ora apontam para o jádito (a memória discursiva, por exemplo, quando colocam a importância do professor como detentor do saber), ora são interpeladas pelas práticas discursivas decorrentes do curso de licenciatura (por exemplo, a importância da interação com os alunos, da facilitação da aprendizagem).

Para dar continuidade e sustentação ao que estamos afirmando, passemos a destacar mais alguns textos que trazem outras identificações ao papel do professor:

É muito importante haver interação entre o aluno e professor, pois acho que quando o aluno participa, ele faz parte do desenvolvimento do raciocínio. [...] a sensação de se ver como professor é incrível, mas para isso acho necessário todo um planejamento e organização sobre todos os assuntos que se pretende trabalhar a fim de se obter bons resultados (B, grifos nossos).

Minha principal estratégia para manter a atenção dos alunos foi inserilos no contexto da aula. Freqüentemente eu pedia por experiências vividas por eles (sobre o tema que estava sendo abordado), perguntava quais doenças entre aquelas citadas os alunos já haviam apresentado, e principalmente, utilizava exemplos comuns para eles. Tentei deixar a aula a mais descontraída possível, para que ninguém ficasse tímido, e todos participassem. A interação com as crianças me fez despertar para algo que até então não tinha me dado conta: como é gostosa a sensação de ensinar algo novo para alguém; de, com seus conhecimentos poder mudar alguma coisa na vida destas pessoas ( $\mathrm{E}$, grifos nossos). 
Criamos algumas estratégias para fazer com que todos participassem pelo menos um pouco. A forma que encontramos de fazer isso foi dividindo os alunos em duplas na hora de mostrar os animais fixados. Dessa forma conseguíamos uma melhor interação, já que estes estavam em menor número e podíamos conversar com eles quase que individualmente. Acho importante que essa experiência tenha nos mostrado que com esforço e comprometimento se consegue melhorar a qualidade de ensino ( $\mathrm{J}$, grifos nossos).

Os fragmentos apontam que esses três licenciandos se identificaram e se reconheceram no papel de professor desejado: aquele que produz interação com os alunos, que consegue fazê-los participar, que traça planos de ação e que almeja atingir algo. Suas declarações expressam certa positividade no âmbito do realizado, resultando na satisfação com o papel de professor assumido, o que evidencia que o julgamento positivo deve-se, antes de tudo, ao alcance ou realização de um ideal, de uma definição de professor, de buscar resultados ante a situação atual.

\section{A escrita do licenciando e o ser professor: algumas considerações}

Em primeiro lugar queremos chamar a atenção para a posição do locutor no texto, pois há grande subjetivação nas produções escritas, oportunidade em que se expuseram, apontaram suas faltas, falaram de suas emoções, enfim, comprometeram-se com os enunciados feitos; os locutores manifestaram ${ }^{1}$ assim suas singularidades e identificações. Somos assim partidários de que o professor deva se imbricar com aquilo que enuncia, que produza um discurso próprio, que expresse as marcas de seu dizer, entendendo que,

Todo dizer e o agir diferenciados de que dão provas os sujeitos no percurso de suas vidas encontram referência última nos movimentos identificatórios desses sujeitos, que são, por assim dizer, ações subjetivas inconscientes e não atribuições a eles conferidas por alguma instância que lhes é externa (CORACINI, 2003, p. 252).

1. O que, a nosso ver, está relacionado aos gêneros escolhidos pelos licenciandos, requerentes de uma linguagem menos formal e acadêmica à qual estão acostumados a escrever ao longo do curso. 
Assim, procurar entender o atual licenciando e futuro professor, na sua singularidade, portanto no seu interior, é também a tentativa de compreender a partir do seu dizer aquilo que lhe é constitutivo: os saberes, as imagens, o dizer do outro, ou seja, aquilo que lhe é dito, pois "o sujeito mais é dito do que diz" (CORACINI, 2003, p. 253). É investigar e descrever essa identidade, do "eu professor", que imagina a si próprio sob a perspectiva do outro (o aluno, o professor formador, o professor da escola), quando este fala sobre sua identidade profissional (as identificações que o constitui), ou seja, aquilo que imagina ser visto por outros. Esse foi um caminho para compreendermos a expressão do desejo de ser o professor que esperam que ele seja (que promova interações com os alunos, que aborde o conhecimento em profundidade de maneira compreensível, que saiba bem sobre o que pretende ensinar etc.).

Dito isso, queremos argumentar em favor da inclusão de práticas de escritura como processo formativo, particularmente dos gêneros adotados, pois a vemos como estimuladora de subjetividades na medida em que coloca, como vimos, o locutor numa posição enunciativa que possibilite também a manifestação de si próprio, de um conhecimento próprio, de sentidos relacionados ao ser e estar professor, permitindo adicionalmente a inscrição desse sujeito, podemos dizer agora, também como produtor de linguagem e de conhecimento na profissão docente.

Assim, a despeito da natureza intersubjetiva na constituição das identidades dos licenciandos, os textos analisados revelam também a possibilidade de construção de identidades discursivas diferenciadas e alternativas quanto ao "ser professor", o que revela processos de subjetivação diferenciados, fundamentados no fato de estarem como sujeitos interpelados pelo espaço e discurso escolar, o que fica evidente quando manifestam a alternância de posições que dá constituição ao futuro professor. Isso porque, como vimos, o locutor ocupa, à maneira de um jogo, papéis de professor ideal, de professor real, de aluno etc. Trata-se da possibilidade de, ao passar por essa experiência de deslocamentos, surgir como desvio de uma identidade que o assujeita, um "eu professor" próprio dentre os futuros biólogos que até então apenas tinham olhos para o bacharelado.

Para finalizar, argumentando em favor dessa possibilidade, destacamos a fala de uma licencianda que mostra exemplarmente o que foi esse processo,

Sei que esse dia mexeu muito comigo, inúmeras sensações ao mesmo tempo, alegria e satisfação lado a lado com a angústia e a aflição. E mais uma vez pensei muito na formação que estamos tendo dentro da universidade. Que tipo de pessoas estão sendo formadas dentro da universidade? Será necessário e importante desprezar o lado emotivo e 
sensível dos estudantes? Qual a relação que temos com a realidade? Quais sentimentos adquirimos ao longo da nossa formação com relação ao nosso dever perante a sociedade? Que universidade é essa? (G)

Escrever sobre a própria prática, uma possibilidade de assumir ou de construir uma identidade, eis a questão.

\section{REFERÊNCIAS}

BALOCCO, Anna E. A escrita e o escrito: produzindo identidades, domesticando diferenças. In: MARIANI, B. A escrita e os escritos: reflexões em análise do discurso e em psicanálise. São Carlos: Claraluz, 2006.

CARVALHO, Cristina. Leitura e a escrita na formação de professores. Teias, v. 3, n. $5,2002$.

CORACINI, Maria J. Subjetividade e identidade do(a) professor(a) de português. In: . (Org.). Identidade \& discurso. Campinas: Unicamp; Chapecó: Argos, 2003.

CRISTÓVÃO, Vera L. L. Modelo didático de gênero como instrumento para formação de professores. In: MEURER, J. L.; MOTTA-ROTH, D. Gêneros textuais e práticas discursivas. Bauru: EDUSC, 2002.

FIAD, Raquel S.; SILVA, Lílian L. M. Diários de campo na prática de ensino: um gênero discursivo em construção. Leitura: Teoria e Prática, v. 19, n. 35, jul. 2000.

MAINGUENEAU, Dominique. Novas tendências em análise de discurso. Campinas: Pontes, 1989. p. 29-51.

RIOLFI, Claudia Rosa; ALAMINOS, Cláudia. Os pontos de virada na formação do professor universitário: um estudo sobre o mecanismo da identificação. Educação e Pesquisa, v. 33, n. 2, maio/ago. 2007.

SILVA, Maria Helena S.; DUARTE Maria da Conceição. O diário de aula na formação de professores reflexivos: resultados de uma experiência com professores estagiários de biologia/geologia. Revista Brasileira de Pesquisa em Educação em Ciências, v. 1, n. 2,2001 . 